\title{
Subcuticular suture—is it a misnomer?
}

\author{
Syed A. Mashhadi - Charles Yuen Yung Loh
}

Received: 21 April 2010 /Accepted: 3 May 2010/Published online: 22 May 2010

(C) Springer-Verlag 2010

Sir,

The subcutis or hypodermis refers to the layer of tissue lying beneath the dermal layer. It is also where the top-most layer of subcutaneous fat lies. When referring to a subcuticular suture, judging by its name alone, one would expect the suture to lie under the skin i.e. in the subcutaneous fat. However, most of the surgeons in reality place this suture in the deep layer of the dermis

Review of the literature tells us that the origins of the subcuticular suture cannot be attributed to a single surgeon but rather a combined effort by generations of surgeons beginning with Halsted in 1887 [1]. Halsted described his suturing technique of skin closure over the repaired hernia cord by burying interrupted sutures of very fine silk. These sutures were placed in the underside of the skin to include only its deeper layer which is not occupied by sebaceous follicles [1, 2]. Perhaps Halsted was proposing the subcuticular closure of a wound in his description. Since then, the technique has evolved.

The initial theory to close the wound with buried subcuticular sutures was to reduce the rate of infection, [1] but later Davis, in 1919 advocated the role of the subcuticular suture more for aesthetic purposes and hence popularized its use [3]. Further developments in the technique took place in early 1960s when Straith proposed the introduction of an intradermal suture to reinforce, evert and decrease wound dehiscence which subcuticular sutures are unable to achieve [4].

Since then, different papers describe the technique of subcuticular sutures which in fact pass through the dermis rather than the subcutis. So far we have not come across any paper which highlights the fact that subcuticular sutures in fact

\footnotetext{
S. A. Mashhadi $(\bowtie) \cdot$ C. Y. Y. Loh

Great Ormond Street Hospital,

London, UK

e-mail: smashhadi@hotmail.com
}

pass through the dermis. In one paper, the author used the terms intradermal and subcuticular sutures, interchangeably [5]. This can be particularly confusing, especially for trainee surgeons and undergraduate medical students.

The method of skin closure by subcuticular suturing is very popular amongst the surgeons, especially Plastic surgeons. It gives better scarring as compare to interrupted sutures which may produce cross hatching [6]. Also subcuticular sutures are usually absorbable which obviates the need of suture removal, unnecessary pain and inconvenience caused to the patient. It is also cost effective as it prevents the need for an additional visit to the clinic for suture removal.

As the technique evolves, we propose that terminology should be correctly used to avoid any confusion. The term, "intradermal suture" is a more appropriate substitute for the "subcuticular suture" because the suture passes through the dermis rather than being placed underneath in the subcutaneous tissue. The term intradermal is not only anatomically correct but is also self explanatory.

\section{References}

1. Fisher GT, Fisher JB, Stark RB (1980) Origin of the use of subcuticular sutures. Ann Plast Surg 4(2):144-148

2. Halsted WS (1889) The radical cure of hernia. John Hopkins Hospital Bulletin No. 1, p 12

3. Davis JS (1919) Plastic surgery, principles and practice. P. Blakiston, Philadelphia

4. Straith RE, Lawson JM, Hipps JC (1961) The subcuticular suture. Postgrad Med 164

5. Raj J, Davis IC, Leshin B (1994) Through the eye of the needle: saving your running intradermal suture. J Am Acad Dermatol 30 (4):643-644

6. de Waard J, Trimbos B, Peters L (2006) Cosmetic results of lower midline abdominal incision: Donati stitches versus a continuous intracutaneous suture in a randomized clinical trial. Acta Obstet Gynecol Scand 85(8):955-959 